\title{
CONHECIMENTO, INOVAÇÃO E SUSTENTABILIDADE NO SETOR TRADICIONAL: O CASO DOS ARTESÃOS DE PETROLINA - PE.
}

\author{
KNOWLEDGE, INNOVATION AND SUSTAINABILITY IN THE \\ TRADITIONAL SECTION: THE CASE OF CRAFTSMANS IN PETROLINA \\ - PE.
}

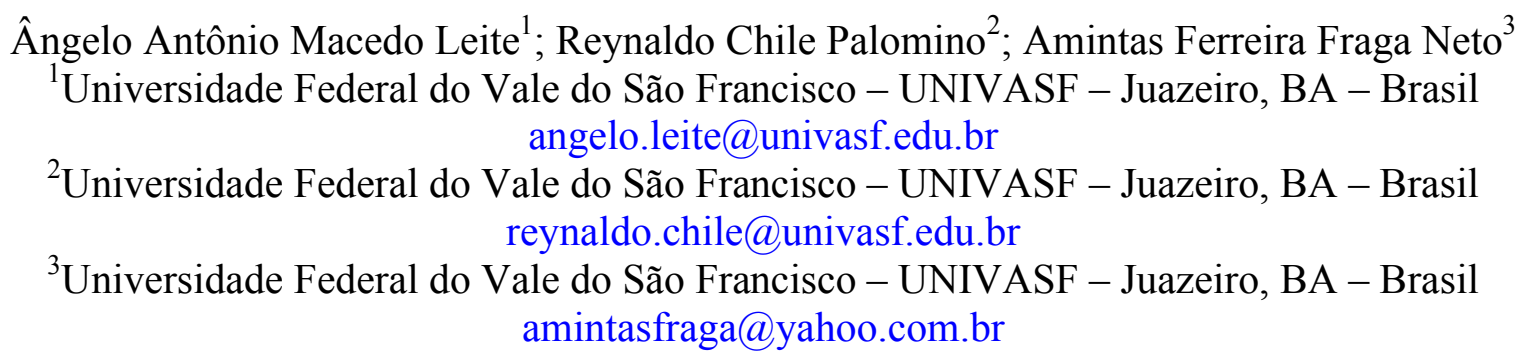

\begin{abstract}
Resumo
A indústria do artesanato representa uma importante fonte de renda e trabalho. Em um país com dimensões continentais e com desigualdades sociais acentuadas simboliza o desenvolvimento de populações de baixa renda pautado na dignidade que o trabalho garante ao homem. Do ponto de vista quantitativo representa 2,8\% do PIB nacional, superando a indústria automobilística. Dentre as atividades econômicas o artesanato está mais ligado e influenciado pelas condições do meio ambiente, mesmo que o profissional dessa área nem sempre esteja preocupado com a preservação do memo. A importância social e econômica justifica as propostas de estudo que viabilizem o desenvolvimento da atividade sem perder o foco na preservação ao meio ambiente. Dentro dessa proposta, o estudo do conhecimento e suas interações, como base na preservação $e$ desenvolvimento das técnicas produtivas é oportuno. O conhecimento tácito é importante para qualquer artesão, uma vez que necessita de tal conhecimento para executar seu ofício. Esse trabalho expõe uma avaliação da variável Conhecimento realizada com a um grupo de artesãos na cidade de Petrolina-PE e foi baseado nas possiveis interações dentre as definições epistemológicas do conhecimento - tácito e explicito - integradas na espiral do conhecimento. Um importante aspecto observado diz respeito à aprendizagem inconsciente apontando que a transmissão de conhecimento e informações não exige a existência de canais ou códigos de informações como é geralmente proposto. Convívio, interação e observação coletiva são responsáveis por garantir a troca de conhecimentos entre os indivíduos.
\end{abstract}

Palavras-chave: conhecimento, sustentabilidade, artesanato. 


\section{Introdução}

O cenário econômico e industrial são passivos de rápidas modificações e exigem das empresas e organizações inseridas nesse espaço capacidade de adaptação, sensibilidade às mudanças e respostas rápidas às exigências comerciais. A necessidade de assimilação de um número crescente de informações aliada as estratégias de gestão tecnológica tornou-se aspecto decisivo para diferenciação empresarial dentro do cenário econômico mundial que se apresenta tão competitivo. Além dessas, outra importante ferramenta utilizada para gerar crescimento nos lucros operacionais nas empresas é a chamada gestão do conhecimento (GC); a qual cria uma vantagem competitiva sustentável e de difícil imitação, pois sua base de sustentação está nos funcionários das empresas, e não nos recursos físicos, os quais podem ser facilmente copiados pela concorrência.

Para qualquer abordagem baseada na GC, uso do conhecimento de forma coesa e integrada aos processos de negócios da empresa para gerar vantagem competitiva, deve compreender um conjunto de diretrizes e recomendações básicas, as quais se encontram sintetizadas em Silva (2002). Estas diretrizes e recomendações básicas podem ser avaliadas seguindo diversas abordagens. Duas das abordagens mais disseminadas que buscam mensurar estrategicamente a aprendizagem e o conhecimento são as seguintes:

a) o capital intelectual, que permite avaliar os recursos não-tangíveis da empresa, envolvendo marcas e patentes, e o conhecimento e aprendizado que as pessoas de uma empresa adquirem ao longo do tempo (Edvinsson e Malone, 1998) e;

b) o balanced scorecard (Kaplan e Norton, 1997), que se preocupa com medições da capacidade de aprendizagem da empresa, como forma de apoiar seus esforços estratégicos.

Existe um número considerável de estudos sobre essa temática que passa a ser valorizada em todos os ramos da economia global. Neste sentido, a proposta desse trabalho é analisar a aprendizagem e o conhecimento dos artesãos na cidade de Petrolina-PE a partir de uma pesquisa desenvolvida com base em estratégias de GC.

A atividade artesanal está inserida no ramo tradicional de produção onde, por questões estruturais, sofre menor influência das variações mercadológicas. Apesar disso, cabe estudar a variável conhecimento nesse setor que representa 2,8\% do PIB nacional (LIRA, 2004), superando a indústria automobilística, já que o conhecimento específico é um dos principais insumos da indústria artesanal.

A cidade de Petrolina é rica em artesanato, estudá-lo significa compreender a estrutura produtiva deste setor na cidade. Sabe-se que a manutenção ou sobrevivência dessa atividade 
econômica está baseada no repasse de técnicas primordiais para a confecção de esculturas e diversos objetos que exigem uma habilidade prática específica. Existem algumas pesquisas que analisam o processo de transferência de conhecimento em determinados setores industriais. Porém, apesar da importância do conhecimento para qualquer tipo de organização, seja ela uma empresa de alta tecnologia ou uma oficina de artesanato, as referências acerca deste tema nesta região são escassas.

Esse trabalho apresenta informações de conteúdo técnico estrutural para fornecer dados sobre o comportamento organizacional da indústria do artesanato e está baseado na conclusão de um projeto de pesquisa. O levantamento bibliográfico, desenvolvido em uma das etapas do projeto de pesquisa, deu base às etapas de observação do processo produtivo, aplicação de questionários e realização de entrevistas atentando para princípios básicos de etnografia na abordagem e análise dos dados.

\section{Fundamentação teórica}

Uma das ferramentas mais utilizadas para ilustrar e diagnosticar iniciativas eficazes de transmissão do conhecimento é conhecido como Espiral do Conhecimento. Essa metodologia desenvolvida por Nonaka e Takeuchi (1997) objetiva ilustrar os processos de inter-relação entre as duas classificações do conhecimento propostas que são: o conhecimento tácito e explícito. $\mathrm{O}$ conhecimento tácito (formato tácito) é representado pelo conhecimento subjetivo como habilidades inerentes a uma pessoa; percepção e experiência, etc que dificilmente pode ser formalizado, transferido ou explicado a outra pessoa. O conhecimento explícito (formato explícito), por sua parte, é o tipo de conhecimento, que pode ser facilmente formalizado em textos, gráficos, tabelas, figuras, desenhos, diagramas, etc, sendo publicado, tanto em papel quanto em formato eletrônico; sendo de fácil transferência e reutilização. codificar, transferir e utilização posterior.

De acordo com Nonaka e Takeuchi (1997), para existir um trabalho efetivo com o conhecimento, deve haver uma conversão constante entre esses dois tipos de conhecimento. Essa conversão dá-se em quatro modos, conforme mostra a figura 01 (NONAKA e TAKEUCHI, 1997). 
Figura 01 - Espiral do Conhecimento

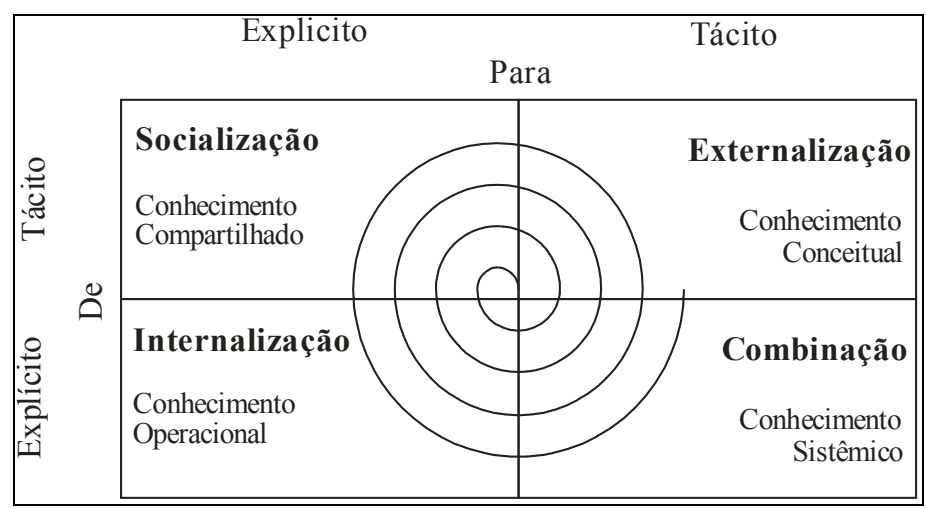

Fonte: Nonaka e Takeuchi, 1997

- Socialização: "é um processo de compartilhamento de experiências e, a partir daí, da criação do conhecimento tácito, com modelos ou habilidades técnicas compartilhados. Um indivíduo pode adquirir conhecimento tácito diretamente de outros, sem usar a linguagem. Os aprendizes trabalham com seus mestres e aprendem sua arte não através da linguagem, mas sim através da observação, imitação e prática”. (NONAKA E TAKEUCHI, 1997 p. 69);

- Externalização: é um processo de articulação do conhecimento tácito em conceitos explícitos. É um processo de criação do conhecimento perfeito, na medida em que o conhecimento tácito torna-se explícito sob a forma de metáforas, analogias, conceitos, hipóteses ou modelos.... O modo de externalização normalmente é visto no processo de criação do conhecimento e é provocado pelo diálogo ou pela reflexão coletiva. (NONAKA e TEKEUCHI, 1997, p. 71). Dentre os quatro modos de conversão do conhecimento a externalização é a chave para a criação do conhecimento, pois cria conceitos novos e explícitos a partir do conhecimento tácito;

- Internalização: “é o processo de incorporação do conhecimento explícito no conhecimento tácito. É intimamente ligado ao "aprender fazendo"... Para que o conhecimento explícito torne-se tácito, é necessária a verbalização e diagramação do conhecimento sob a forma de documentos, manuais ou histórias orais" (NONAKA e TAKEUCHI, 1997 p 77-78);

- Combinação: A combinação é um processo de sistematização de conceitos em um sistema de conhecimento. Esse modo de conversão do conhecimento envolve a combinação de conceitos diferentes de conhecimento explícito (NONAKA E TAKEUCHI, 1997).

\section{Materiais e métodos}

Inicialmente realizou-se um levantamento dos principais locais onde eram praticadas atividades artesanais em Petrolina. Este levantamento teve por objetivo identificar os locais mais 
adequados para se desenvolver um estudo sobre o conhecimento. Foram priorizados aqueles que concentravam maior número de artesãos e produtividade mais elevada. Optou-se por fazer o estudo nos dois locais mais representativos do artesanato Petrolinense: A Oficina do Artesão Mestre Quincas e o Centro de Artesanato Ana das Carrancas. O Centro de Artesanato Ana das Carrancas funciona hoje como um museu das peças da artesã, escola de xadrez para crianças em risco social e como ateliê para as duas filhas da artesã Ana das Carrancas (principal representante do artesanato no século XX).

Optou-se posteriormente por focalizar a pesquisa na Oficina do Artesão, uma vez que lá o nível de produção é maior e envolve um número de artesãos mais elevado, viabilizando a análise da transmissão das técnicas de confecção entre os atores.

A metodologia utilizada nesta pesquisa segue o delineamento exploratório baseado em levantamentos realizados no universo da população estudada e pesquisas bibliográficas a respeito do tema proposto (conhecimento e aprendizagem).

Estudos sobre princípios básicos de etnografia foram essenciais para a aplicação de questionários e realização de entrevistas com os artesãos.

Foram realizadas várias visitas com o objetivo de compreender ao máximo a dinâmica da atividade e as relações entre os artesãos. Em algumas dessas visitas foram realizadas entrevistas e observação do trabalho praticado (estratégias de produção, organização do local, relacionamentos entre os artesãos e outras variáveis de interesse), objetivando responder questões levantadas a partir da pesquisa bibliográfica.

O levantamento bibliográfico foi direcionado à compreensão dos mais importantes conceitos da Gestão do Conhecimento. Foram adotados os conceitos de aprendizagem e conhecimento desenvolvidos principalmente em Nonaka e Takeuchi (1997); Fleury e Fleury (1997); Bukowitz e Willians (2002). Como os dados colhidos partiram da observação científica, foi realizado um estudo preliminar sobre conceitos básicos de etnografia disponíveis em Mattos (2001); tais conceitos deram direcionamento às análises sobre os sujeitos envolvidos na pesquisa.

\section{Resultados e discussões}

\subsection{Caracterização do público pesquisado.}

Foi realizado um levantamento estatístico com o objetivo de identificar o perfil social dos artesãos da Oficina do Artesão Mestre Quincas, além disso, desenvolver uma análise quanto à visão dos mesmos sobre a importância do conhecimento adquirido, do ambiente de trabalho e das condições físicas do local. Utilizou-se um questionário qualitativo a uma população de 14 artesãos e observou-se um perfil social variado com população de faixa etária distribuída dos 31 aos 70 anos, 
sendo que $64 \%$ desta população encontram-se em estado civil casado (a) e possuem número médio de dependentes heterogêneo; $29 \%$ deles não possuem nenhum dependente e cerca de $36 \%$ possuem cinco ou mais dependentes.

O ingresso na atividade artesanal dar-se principalmente no período dos 11 aos 20 anos de idade, o que pode ser ilustrado pelo questionário aplicado que aponta cerca de $50 \%$ dos entrevistados relatando que iniciaram a atividade dentro dessa faixa etária.

Para 50\% dos artesãos o aprendizado do ofício ocorreu a partir de familiares ou amigos. Chama atenção um número expressivo de cerca de $43 \%$ dos entrevistados afirmando que aprenderam a profissão sozinhos e apenas 7\%, ou seja, 1 (um) artesão alegou ter aprendido o ofício de um professor.

Dentre os principais motivos apontados para ingressarem na profissão de artesão estão: a oportunidade de possuírem o próprio negócio, além de reconhecerem que nasceram com o dom da arte. Complementa essa informação o fato de cerca de $86 \%$ dos entrevistados relatarem que freqüentemente inventam novos tipos de artesanato, incluindo novas formas e métodos de confecção.

Aproximadamente $64 \%$ dos artesãos confirmam a participação em cursos e palestras dentro da respectiva área de trabalho. Ressalta-se que, em sua maioria, tais palestras e cursos eram direcionados ao trabalho coletivo e ao associativismo e que iniciativas de cursos sobre aprimoramento de técnicas de confecção eram raras.

Cerca de $86 \%$ dos entrevistados afirmam que já ensinaram ou ensinam o ofício de artesão a outras pessoas. As principais justificativas são: ensinar para ajudar outras pessoas a possuírem uma profisssão digna, confirmando a importância da atividade artesanal na inclusão social; muitos deles relatam a preocupação com o futuro da profissão uma vez que o número de interessados em aprender o ofício é reduzido (Figura 02).

Figura 02: Principais motivos para ensinar artesanato. 


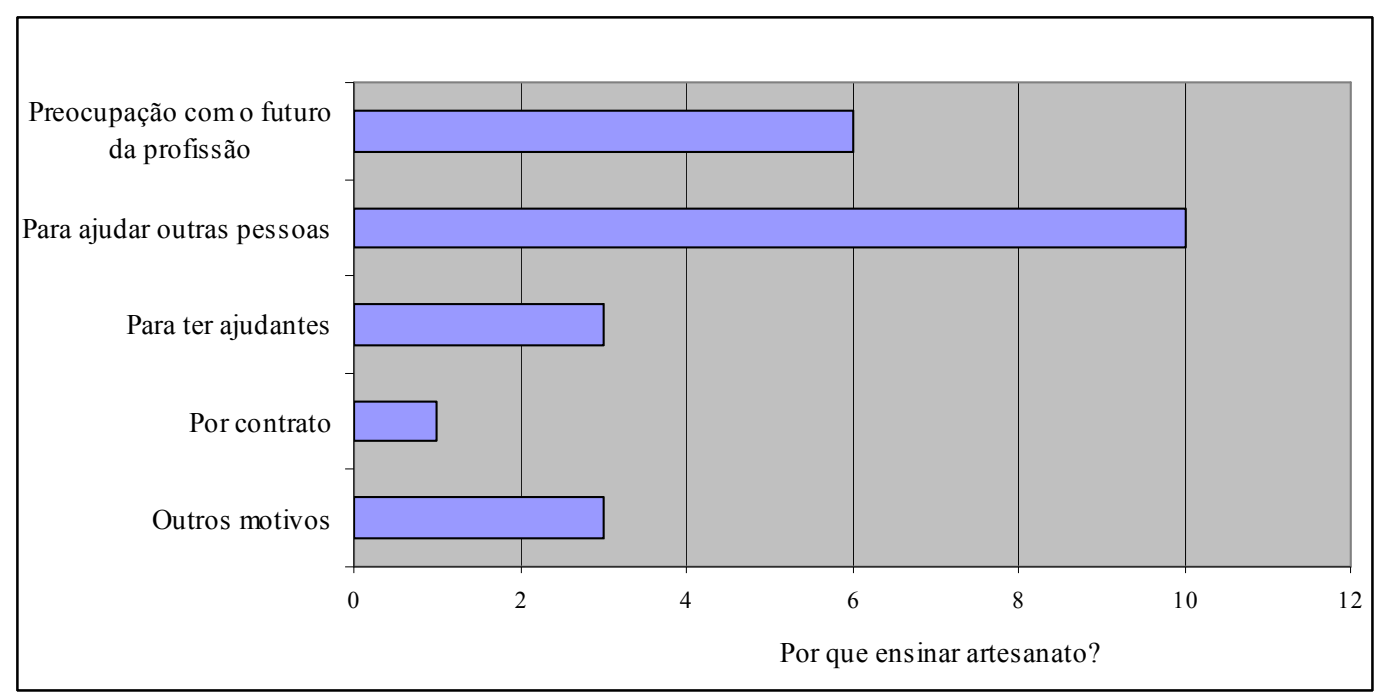

Fonte: pesquisa de campo

Quando abordados a respeito da importância do conhecimento no setor artesanal responderam: 100\% dos entrevistados reconheceram a importância do conhecimento para a atividade, 64\% afirmaram que conseguem ter novas idéias na Oficina do Artesão, 79\% admitem troca de sugestões com colegas de trabalho, apenas 36\% relatam a necessidade de máquinas para facilitar o trabalho e $43 \%$ confirmam a necessidade de inovar para alcançar novos mercados (Figura $03)$.

Figura 03: Opinião dos artesãos sobre o conhecimento.

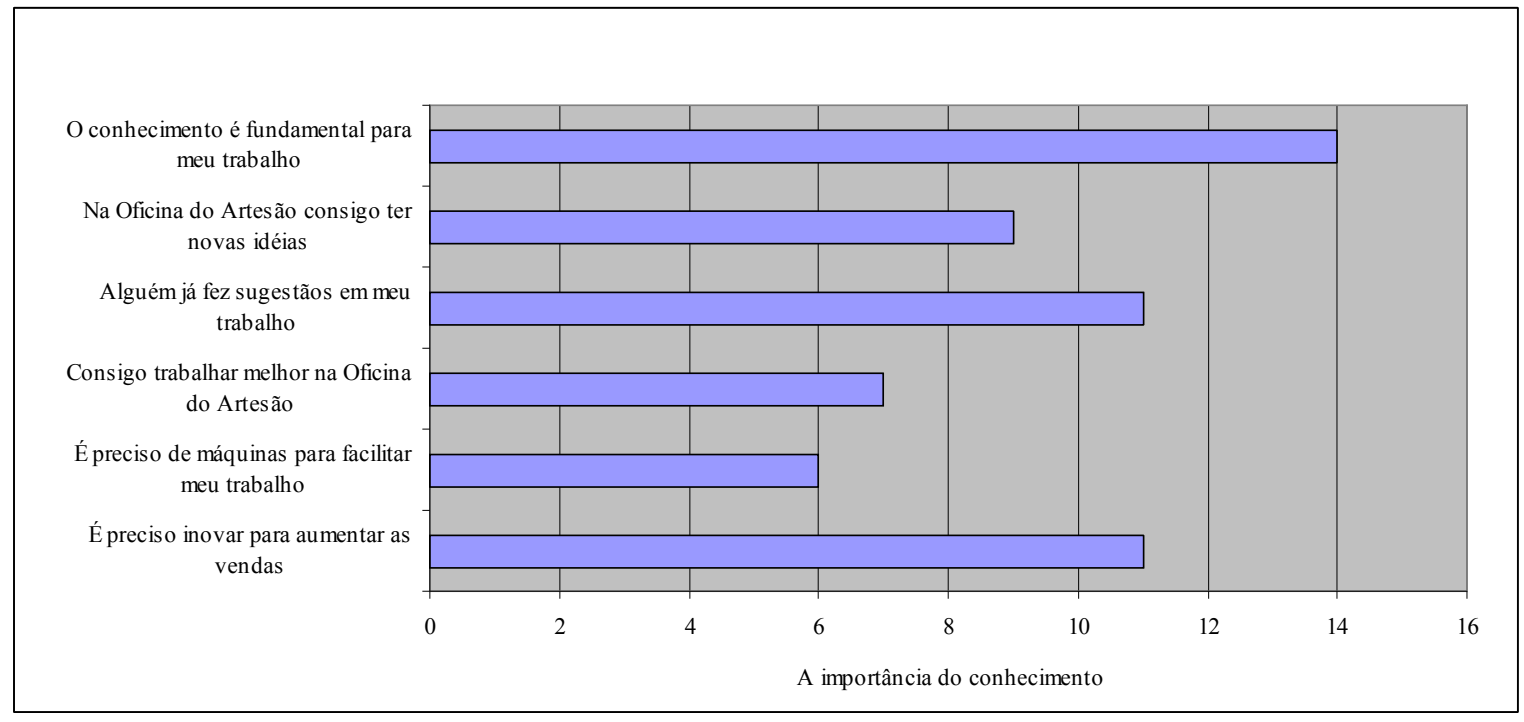

Fonte: pesquisa de campo

Dentre as principais necessidades apontadas pelos entrevistados para melhoria na Oficina do Artesão estão: o investimento em divulgação do local, apoio governamental e financeiro além de parcerias com escolas e universidades apontada como prioridade por cerca de $86 \%$ dos artesãos. 


\subsection{Respostas aos objetivos}

Em resposta ao objetivo geral do projeto de pesquisa, a análise do processo de transmissão do conhecimento entre os artesãos esteve baseada em um estudo geral destes processos, com ênfase na estrutura organizacional, seguindo exemplos de organizações onde o repasse de técnicas, cognições e informações entre os atores é considerado estratégico do ponto de vista gerencial, suavizando as perdas de know-how dessas organizações.

Uma preocupação tomada foi a averiguação de características peculiares do local estudado que pudessem influenciar na aplicação e extensão dos resultados obtidos na analise geral dos processos de transmissão do conhecimento.

Caracteriza-se a Oficina do Artesão Mestre Quincas como local de produção de peças artesanais onde os artífices convivem no mesmo espaço físico dando margem à confluência interativa em diversas formas. Dentre as características peculiares do local, que exigem uma analise diferenciada das fases de troca de informações está a escassez de diálogo objetivo, no que tange a transmissão de técnicas de confecção. Essa característica básica confere uma deficiência lógica da presença do conhecimento explicito neste processo, uma vez que este tipo de conhecimento é caracterizado por ser tangível e o diálogo é um meio adequado para transmissão desse tipo de conhecimento.

Como então explicar a toca de cognições entre os artesãos de Petrolina?

Outra importante característica foi observada a partir das analises das peças produzidas pelos artesãos. Uma preocupação local é a não concorrência entre os escultores, ou seja, cada artesão segue um estilo diferente evitando produzir peças semelhantes e a concorrência. Apesar disso, existem características visuais nas peças de todos eles, advindas do processo produtivo que conferem semelhanças entre elas. Convencionou-se chamar essa troca de informações por aprendizagem inconsciente. Esse processo não depende de canais de informação ou de mecanismos explícitos de interação entre os indivíduos. Parte do convívio comum. É a troca de cognições a partir da observação direta, ou seja, o comportamento e as ações de um indivíduo influenciando os outros e assim reciprocamente.

Além da transmissão do conhecimento entre os próprios artesãos, foram analisadas possíveis iniciativas de repasse das técnicas artesanais a aprendizes em geral. Uma das principais dificuldades apontadas diz respeito à falta de interesse dos próprios aprendizes em perseverar a aprender o ofício de artesão. A aquisição das técnicas de produção, nesse caso, exige um período mínimo de tempo além de esforço e os resultados financeiros durante esse tempo são insuficientes. Desde o período quando se inicia o contato com a produção de esculturas até quando é possível ganhar dinheiro com 
a atividade existe um intervalo de tempo considerável. Esse seria um dos principais motivos para o baixo número de interessados em aprender o ofício.

A espiral do conhecimento, fundamental para analisar o processo de criação de conhecimento nas organizações, pode ser adaptada e utilizada para entender o processo de criação e a dinâmica do conhecimento entre os artesãos de Petrolina (Figura 04).

Figura 04: Espiral do conhecimento no setor artesanal de Petrolina

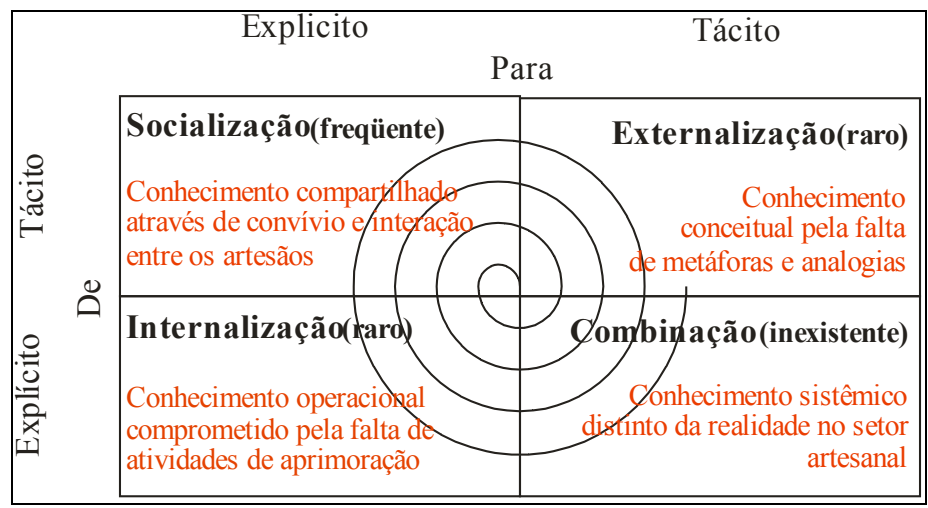

Fonte: Adaptado de Nonaka e Takeuchi, 1997.

A adaptação da espiral do conhecimento advém das especificidades encontradas no setor artesanal de Petrolina. A distinção entre os setores tecnológico e tradicional exige adaptações na metodologia disponível.

\subsubsection{A socialização do conhecimento entre os artesãos}

Como foi visto, esse modo de conversão do conhecimento está profundamente ligado aos conceitos de experiência e prática além de não exigir uma comunicação lingüística aprofundada entre os indivíduos e sim um espaço de convívio e interação contínua. No setor artesanal, o repasse de técnicas de produção pode ser definido como um processo de socialização.

Através da pesquisa realizada a alguns artesãos na cidade de Petrolina-PE foi possível confirmar essas características. Os artesãos envolvidos na pesquisa convivem em um ambiente comum de produção e interatividade. Apesar de o ambiente favorecer às trocas de informações a respeito das técnicas produtivas, esse tema não é tão comum no diálogo entre os mesmos. Entre eles 
é rara a troca de sugestões sobre o trabalho alheio. No entanto, o simples convívio e observação são responsáveis por transferir conhecimento entre os artesãos. Convencionou-se designar esse processo por aprendizagem inconsciente. A efetivação desse aprendizado pode ser observada na semelhança entre as peças confeccionadas pelos artesãos que compartilham o mesmo espaço de trabalho.

Apesar de adotarem a estratégia da não concorrência, ou seja, cada um produz peças em estilo próprio e diferenciado dos demais, existem semelhanças no artesanato produzido por todos, geradas no processo produtivo, que demonstram um compartilhamento das técnicas de produção. Essa transmissão de informações somente pode ser explicada pela observação e/ou convívio, uma vez que se constatou baixo nível de comunicação oral sobre processos produtivos entre os artesãos.

\subsubsection{A externalização do conhecimento entre os artesãos}

Entre os artesãos a externalização só pode ocorrer se houver um intercambio de informações. Deve existir uma base de diálogo que favoreça a criação de conceitos análogos ou metafóricos sobre os processos de produção ou sobre o modo de percepção da realidade como escopo ao processo criativo.

Como a externalização basea-se na conversão do conhecimento tácito em conhecimento explícito, existe uma necessidade de um meio de explicitar as cognições de cada artesão. Esse meio poderia ser uma reunião informal para troca de informações, assim como a iniciativa de ensinar as técnicas de produção artesanal a outros indivíduos. Nesse segundo método, a necessidade de se comunicar ou transferir informações geraria um desenvolvimento pessoal na criação de metáforas, analogias e até mesmo de informações codificáveis entre cada mestre-artesão. No entanto, foram observadas poucas atividades desse tipo, o que acaba por comprometer o processo de externalização do conhecimento entre aqueles artesãos.

\subsubsection{A internalização do conhecimento entre os artesãos}

No caso específico do setor artesanal a internalização só poderia ocorrer se houvesse iniciativas de treinamento e aperfeiçoamento, onde lidassem com informações explícitas e a partir delas aprimorassem suas habilidades. Atualmente atividades desse tipo são raras entre os artesãos submetidos à pesquisa.

A internalização, como processo de enriquecimento de habilidades poderia tornar-se estratégia econômica entre os artesãos. Alguns órgãos governamentais tentam ingressar nesse campo, no entanto, segundo palavras dos próprios artesãos, essa aproximação nem sempre é bem vinda. O processo de internalização do conhecimento entre eles fica então comprometido. 
O típico da gente é a carranca. Andou um pessoal do SEBRAE aqui querendo mudar o estilo do trabalho dos artesãos de Petrolina. Não tem como! Eles estavam querendo que agente passasse a fazer umas esculturas magrinhas, como existe lá em Sertânia. A gente disse não! (Gabriel Pereira, artesão).

\subsubsection{A combinação do conhecimento entre os artesãos}

A combinação como processo de conversão de conhecimento depende de comparação e análise de informações explicitas na tentativa de obter novas informações a partir daquelas analisadas, por tudo isso é considerada distante da realidade dos artesãos, componentes de um sistema tradicional de produção, que pouco lidam com informações explícitas.

\subsection{Artesãos de Petrolina e o desenvolvimento sustentável}

Além da análise do conhecimento e aprendizagem entre os artesãos, foram realizadas algumas abordagens sobre a matéria-prima utilizada, sabendo da importância que o tema Desenvolvimento Sustentável adquiriu nos últimos anos e da estreita relação entre a produção artesanal e o contingente cada região.

O setor artesanal, por características naturais de dependência ao meio ambiente, está diretamente afetando e sendo afetado pelo meio. Como a maioria da matéria-prima utilizada por qualquer artesão é retirada diretamente da natureza, a escassez desta, produzida por vários fatores, está afetando o trabalho e mentalidade desses profissionais. Além disso, a extração descontrolada dos recursos naturais, por parte dos artesãos, provoca desequilíbrios ambientais irreversíveis.

Em entrevista realizada à presidente da FACARPE (Federação das Associações, Cooperativas e Grupos Produtivos de Artesãos de Pernambuco), obteve-se a informação que cerca de $60 \%$ a $70 \%$ da atividade artesanal é praticada utilizando matéria primas advindas da natureza. São escultores, modeladores, ceramistas, coureiros, carpinteiros e tantos outros que extraem diretamente da natureza seus meios de produção e muitas vezes de subsistência.

Dentro do tema desenvolvimento sustentável, objetivou-se analisar como os escultoresartesãos da cidade de Petrolina-PE, que utilizam a madeira da Umburana (Commiphora leptophloeos) como matéria prima para suas esculturas, estão vivenciando as novas propostas de “desenvolvimento sustentável" que segundo Cavalcante (2003, p.18) Trata-se de deslocar a ênfase do crescimento contínuo da economia para o compromisso da preservação do meio ambiente.

Os escultores utilizam apenas a madeira da Umburana como matéria prima e afirmam que não enfrentam problemas em adquirir-la, pois é retirada a partir das áreas destinadas a instauração de projetos de irrigação que estão em expansão no vale do São Francisco. Alguns autores fazem 
críticas aos artesãos pelo processo de agravamento do desequilíbrio ambiental, baseados na confirmação de que a Umburana tem importância vital na biodiversidade desse ecossistema, além de ser uma espécie única da caatinga e de estar em risco de extinção. Os artesãos se defendem, afirmando que os maiores responsáveis pela extração da Umburana na região citada são os grandes proprietários de terra que desejam investir no cultivo de frutas na região do submédio São Francisco. Relatam ainda que apenas utilizam para "fins nobres" a madeira que, por ventura, iria ser queimada ou vendida como estacas para cercar as fazendas.

Apesar de não reconhecerem-se como os principais responsáveis pela extração da Umburana, os artesãos não deixam de pensar no futuro da atividade atentando para a preservação da espécie. Através deles, surgem idéias de projetos de replantio da Umburana que, apesar de ainda não tão eficazes, traduzem o ideal de preservação ambiental dos mesmos.

\section{Considerações finais}

A pesquisa realizada tornou possível a observação aprofundada do convívio entre os artesãos pesquisados assim como do processo produtivo praticado na Oficina do Artesão Mestre Quincas. Um importante aspecto obsevado neste trabalho, que de certa forma contraria algumas definições existentes na literatura sobre o tema, diz respeito a aprendizagem inconsciente. Segundo esse aspecto, a transmissão de conhecimeto e informações não exige necessariamente a existência de canais ou códigos de informações capazes de trasmitir as informações desejadas, como é geralmente proposto. O simples convívio, interação e observação coletiva são responsáveis por garantir a troca de cognições entre os indivíduos.

Esse fluxo de cognições acaba por enquadrar os indivíduos envolvidos no processo de interação em um grupo comum que praticam as atividades que, na realidade, foram desenvolvidas por todos. Ainda segundo o conceito de aprendizagem inconsciente, todo indivíduo envolvido no processo é capaz de gerar cognições nos outros. A capacidade de absorver as informações é que varia de um indivíduo para o outro.

As técnicas de gestão do conhecimento disponíveis na literatura especializada geralmente estão ligadas ao setor produtivo tecnológico. As informações e procedimentos baseam-se na existência de um grande e contínuo fluxo de informações que devem atingir todos os ramos da organização. Além disso, existe ainda a necessidade de filtrar as informações proveitosas para o desenvolvimento de uma cultura de inovação para as empresas.

O setor artesanal, resguardado das oscilações mercadológicas dos grandes centros comerciais, não sofre tantas influências externas a ponto de se modificar tão rapidamente quanto os setores dependentes da alta tecnologia. No entanto depende naturalmente da manutenção do 
conhecimento de seus atores. Portanto, entender o comportamento dessa variável implica compreender os aspectos estruturais do setor.

A pesquisa de campo apontou que $100 \%$ dos artesãos reconhecem a importância do conhecimento na atividade que praticam. Apesar de possuírem baixo nível de escolaridade, como é comum no setor artesanal, compreendem a importância de adquirirem novos conhecimentos e aprimorarem as técnicas produtivas.

A adaptação e aplicação da metodologia disponível na diagnosticação e gestão do conhecimento no setor artesanal também merece destaque. As peculiaridades do público pesquisado geraram a necessidade de remodelar algumas estruturas propostas na literatura. $\mathrm{O}$ ambiente externo e as interações entre os artesãos foram ponderadamente analisadas a fim de evitar a ocorrência de erros na análise e interpretação dos dados colhidos na pesquisa.

O desafio do desenvolvimento sustentável é urgente. A busca pela minimização dos impactos ambientais em todos os ramos da sociedade é uma questão de sobrevida humana. Desenvolver atividades que privilegiem a reflexão sobre as melhores formas de utilizar as matériasprimas não-renováveis ou que exigem determinado tempo para renovação é um passo importante rumo ao manejo sustentável.

A atividade artesanal está diretamente relacionada com a disponibilidade de recursos naturais para sua manutenção. A extração descomedida desses recursos pode representar escassez e o conseqüente fim da atividade. Compreender as relações entre os artesãos e o meio natural onde realizam sua atividade constitui passo importante para criação de estratégias de manejo sustentável dos recursos explorados.

O poder político público, os artesãos e a sociedade em geral compreendem a necessidade de preservação ambiental, no entanto são raras as iniciativas reais de projetos a médio e longo prazo que privilegiem o manejo ecológico sustentável.

\begin{abstract}
The handicraft represents an important source of revenue and job. In a country with continental dimensions and with social inequalities, it symbolizes the development of populations with low income. From the quantitative point of view it represents $2.8 \%$ of national GDP, overcoming the automobile industry. Among the economical activities the handicraft is linked and influenced by the environment conditions. The social and economical importance justifies the research proposals that make possible the development of the activity without losing the focus in the environment preservation. Inside of that proposal, it is opportune the research about knowledge and its interactions, as base in the preservation and development of the productive techniques. The tacit knowledge is important for any craftsman, once he needs such knowledge to execute an activity. This aim of this paper is to describe the knowledge creation among the craftsman in the city of Petrolina-PE and it was based on the possible interactions among knowledge epistemological definitions - tacit and explicit - integrated in the spiral of the knowledge. An important observed aspect concerns the unconscious learning pointing. Sometimes, the knowledge transmission and information don't demand the existence of channels or codes of information.
\end{abstract}

Key-words: knowledge, sustainability, handicraft. 


\section{Referências}

BUKOWITZ, W. WILLIANS, R. Manual de Gestão do Conhecimento. Porto Alegre: Bookman, 2002.

EDVINSSON, L.; MALONE, M. S. Capital intelectual. São Paulo : Makron Books, 1998.

FLEURY, A. FLEURY, M. T. L. Aprendizagem e Inovação Organizacional: as experiências de Japão, Coréia e Brasil. São Paulo: Atlas, 1997.

KAPLAN, R. S.; NORTON, D. P. A estratégia em ação: balanced scorecard. São Paulo : Campus, 1997.

LIRA, G. R. Artesanato Brasileiro: Cultura que gera negócios. Ministério da Cultura, 2004. Disponível em: http://www.cultura.gov.br/documentos/Artesanato.pdf. Acessado em: 10 jun 2006.

MATTOS, C. L. G. A abordagem etnográfica na investigação científica. Disponível em: $<$ http://br.geocities.com/celem05/abord_etnogr_invest_cient.doc >: Acessado em: 10 jun 2006.

NONAKA, I. TAKEUCHI, H. Criação de Conhecimento na Empresa. Rio de Janeiro: Campus, 1997.

RODRIGUES, Rê. Ana das Carrancas. Disponível em: http://www.cyberartes.com.br Acessado em: 10 jun 2006.

SEBRAE. Série Artesão e Artesanato: Petrolina. Recife, Sebrae/PE. 2000.

SILVA, S. L. Informação e competitividade: a contextualização da gestão do conhecimento nos processos organizacionais. Ciência da Informação, v. 31, n. 2, p. 142-151, maio/ago. 2002.

\section{Dados dos autores:}

Nome completo: Ângelo Antônio Macedo Leite

Filiação institucional: Universidade Federal do Vale do São Francisco - UNIVASF

Departamento: Engenharia de Produção

Função ou cargo ocupado: Professor

Endereço completo para correspondência (bairro, cidade, estado, país e CEP): Av. Antônio Carlos Magalhães, 510, Santo Antônio, Juazeiro - BA, Brasil, 48902-300

Telefones para contato: (74) $3614-1937$

e-mail:angelo.leite@univasf.edu.br

Nome completo: Reynaldo Chile Palomino

Filiação institucional: Universidade Federal do Vale do São Francisco - UNIVASF

Departamento: Engenharia de Produção

Função ou cargo ocupado: Professor

Endereço completo para correspondência (bairro, cidade, estado, país e CEP): Av. Antônio Carlos Magalhães, 510, Santo Antônio, Juazeiro - BA, Brasil, 48902-300

Telefones para contato: (74) $3614-1937$

e-mail:reynaldo.chile@univasf.edu.br 
Nome completo: Amintas Ferreira Fraga Neto

Filiação institucional: Universidade Federal do Vale do São Francisco - UNIVASF

Departamento: Engenharia de Produção

Função ou cargo ocupado: Estudante

Endereço completo para correspondência (bairro, cidade, estado, país e CEP): Av. Antônio Carlos Magalhães, 510, Santo Antônio, Juazeiro - BA, Brasil, 48902-300

Telefones para contato: (74) $3614-1937$

e-mail:amintasfranga@yahoo.com.br

Recebido para publicação em: 05/10/2009

Aceito para publicação em: 10/11/2009 